\title{
Knowledge, attitudes and practices toward prevention of hepatitis B virus infection among medical students at Northern Border University, Arar, Kingdom of Saudi Arabia
}

Mohammed Ali Alhowaish ${ }^{1}$, Jawaher Ali Alhowaish ${ }^{2}$, Yasser Hamoud Alanazi ${ }^{3}$, Muharib Mana Alshammari ${ }^{3}$, Mushref Saeid Alshammari ${ }^{3}$, Nasser Ghadeer Alshamari ${ }^{3}$, Abdulaziz Sael Alshammari ${ }^{3}$, Meshael Kareem Almutairi ${ }^{4}$, Sultan Abdullah Algarni ${ }^{5}$

\footnotetext{
${ }^{1}$ Intern, Faculty of Medicine, Northern Border University, Arar, Saudi Arabia

${ }^{2}$ Resident, Department of Family Medicine, King Fahd Hospital of the University, Alkhobar, Saudi Arabia

${ }^{3}$ Student, Faculty of Medicine, Northern Border University, Arar, Saudi Arabia

${ }^{4}$ Intern, Faculty of Medicine, Imam Abdulrahman Bin Faisal University, Dammam, Saudi Arabia

${ }^{5}$ Finished Internship, Degree of Bachelor of Medicine and Surgery (MBBS), Altaif University, Saudi Arabia
}

\section{Type of article: Original}

\begin{abstract}
Background and aim: Health care workers' risk of occupational exposure to HBV is a chief concern, particularly with young students in the health profession.

This study was carried out to assess the knowledge regarding symptoms, risk factors and prevention of hepatitis $B$ virus infection among medical students.

Methods: A cross-sectional study was carried out from November 01, 2016 to May 30, 2017 on medical students at the Northern Border University (Arar, Kingdom of Saudi Arabia). Data were collected from 200 students from all academic years using pre-designed questionnaire which included questions designed to fulfill the study objectives.

Results: Regarding students' knowledge about hepatitis B infection, $81 \%$ of them knew that carriers could transmit infection, $89.5 \%$ of them knew that it could not be spread by casual contact, $80 \%$ by contact with open wound, $96.5 \%$ by contaminated blood and body fluids, $92.5 \%$ by unsterilized syringe, needle and surgical instruments and $79.5 \%$ by unsafe sex. In total, $86.5 \%$ of students knew that a vaccine could prevent HBV infection, $95 \%$ knew it had been laboratory tested, $64 \%$ knew HBV had post exposure prophylaxis and only $55 \%$ knew that it could be cured. In all, 75.5\% of students knew that HBV caused liver cancer. Regarding attitude, $23 \%$ of students said they had no concern of being infected with HBV, $86.5 \%$ agreed that HBV vaccine was safe and effective and $90 \%$ believed that following infection, control guidelines would protect them from being infected by HBV at work. Regarding practice, only $56.5 \%$ of students had screened for HBV infection $22 \%$ had had a needle prick injury but $68 \%$ would report that injury. Furthermore, $69.5 \%$ have received HBV vaccine but only $38 \%$ of them had received 3 doses.

Conclusion: The students' knowledge of the hepatitis B virus was found to be good. We recommend improving knowledge, attitude and practice of the public as well as students, through health education campaigns and settings.
\end{abstract}

Keywords: Knowledge; Hepatitis B; Medical student; Northern Border University; Arar; Saudi Arabia

\section{Introduction}

Hepatitis B virus (HBV) infection is a worldwide healthcare problem, especially in developing areas. Globally, over 2 billion people have been infected with HBV, and there are over 350 million carriers $(1,2)$. The spread of HBV is usually through body fluids such as blood, semen, and vaginal secretions (3). Consequently, the likely channels for infection of HBV are sexual activity, needle-sharing or an unintentional needle-stick, blood transfusions, and organ

\section{Corresponding author:}

Dr. Jawaher Ali Alhowaish, Department of Family Medicine, King Fahd Hospital of the University, Alkhobar, Saudi Arabia. Tel.: +966546319519, Email: diamond-135@hotmail.com

Received: July 12, 2017, Accepted: August 28, 2017, Published: September 2017

iThenticate screening: August 28, 2017, English editing: September 14, 2017, Quality control: September 20, 2017

(c) 2017 The Authors. This is an open access article under the terms of the Creative Commons Attribution-NonCommercialNoDerivs License, which permits use and distribution in any medium, provided the original work is properly cited, the use is non-commercial and no modifications or adaptations are made. 
transplantation (4-6). Infected mothers can also pass the infection to their newborns during the delivery period (3). HBV cannot be transmitted by holding hands, sharing food, kissing, hugging, coughing, sneezing, or breastfeeding. Acute infection of HBV can cause nonspecific symptoms or fulminant hepatitis that may cause death or require urgent liver transplantation. Chronic infection can be the cause of death associated with liver failure, cirrhosis, or hepatocellular carcinoma. Furthermore, after cigarette smoking, HBV ranks second on the list of known carcinogenic agents that affect humans $(1,2,7,8)$. By adhering to universal precautions which include using protective barriers such as gloves, vaccination, appropriate sterilization of medical equipment, and a suitable hospital waste management system, the spread of HBV infection can be prevented (9-12). The overall prevalence of HBV in Saudi Arabia of $1.7 \%$ and $8.7 \%$ was found among health college students and health care workers, respectively (13). Another study in KSA reported that prevalence of HBsAg in males and females was $0.17 \%$ and $0.78 \%$ respectively in the 18 to 21 -year-olds and $0.39 \%$ and $0.90 \%$ in the 22 to 30 -year-olds (14). Prevalence of the hepatitis B virus infection among health care workers in Tanzania was $7.0 \%$ (15). A previous study was conducted in Ha'il region in Saudi Arabia found that most of the students had enough knowledge about HBV infection and its mode of transmission. Regarding knowledge about vaccination, $81.4 \%$ of students were aware of $\mathrm{HBV}$ vaccine and that it provides protection against HBV infection. However, a relatively low quantity $(40.4 \%)$ of study participants knew that HBV has a post-exposure prophylaxis and that it can be treated/or cured (61.9\%) (16). The aims of this study were to assess the knowledge regarding symptoms, risk factors and prevention of hepatitis B virus infection among medical students and to determine their attitudes towards HBV, at Northern Border University, Arar, Kingdom of Saudi Arabia.

\section{Material and Methods}

\subsection{Study design and setting:}

A cross-sectional study was carried out on medical students at Northern Border University, Arar, Kingdom of Saudi Arabia. This study was conducted during the period from November 01, 2016 to May 30, 2017, on medical students at Northern Border University using a pre-designed questionnaire for data collection.

\subsection{Sampling}

The sample size was calculated using the sample size equation: $n=z^{2} p(1-p) / e^{2}$. Data was collected from 200 students from all academic years. Systematic random sampling technique was followed. The first year in medical school in KSA is a preparatory year, so they were not included in the study. In total, 40 students were randomly chosen from each academic year from the $2^{\text {nd }}$ to the $6^{\text {th }}$ year $(20$ male and 20 female).

\subsection{Measurement tool and data collection}

Data was collected by using a pre-designed questionnaire which included questions designed to fulfill the study objectives (17). Data were collected by means of personal interview with the sampled population. Data collectors gave a brief introduction to students before filling the questionnaire. We tested the reliability of the study by conducting a pilot study. Initially, 20 students were interviewed and asked to fill the questionnaire to test it and to ensure clarity of questions. The 20 students in the pilot study were not included in the study sample. The questionnaire items were the following:

1) Questions covering socio-demographic characteristics of students including sex, marital status and academic year.

2) Questions to discuss knowledge about hepatitis B infection as to whether HBV causes liver cancer, mode of infection, if $\mathrm{HBV}$ carriers can transmit infection, if vaccine can prevent $\mathrm{HBV}$ infection, if $\mathrm{HBV}$ had been laboratory tested and if HBV has post exposure prophylaxis.

3) Questions to discuss the attitude of those students towards hepatitis B infection as to whether HBV vaccine is safe and effective, if all patients should be tested for HBV before they receive health care, if they do not feel comfortable in taking care of people with HBV and if following infection control guidelines will protect from being infected by HBV at work or not.

4) Questions to discuss the practice of those students to protect their patients and themselves from hepatitis B infection as to whether they ever screened for HBV, if they change gloves for each patient during blood taking, if they ever had a needle prick injury and would they report for it, if they were vaccinated against $\mathrm{HBV}$, and the doses of HBV vaccine they had received.

\subsection{Statistical Analysis}

All the data were analyzed using IBM(C) SPSS(C) Statistics version 20 (IBM() Corp., Armonk, NY, USA). Descriptive statistics for the prevalence and quantitative variables were used. 
http://www.ephysician.ir

\subsection{Ethical considerations}

Permission to conduct the study was obtained from the Research and Ethics Committee at the College of Medicine, Northern Border University, Arar, Saudi Arabia. The questionnaire had a brief introduction explaining the aims and significance of the study.

\section{Results}

Table 1 shows the socio-demographic characteristics of the participants, Northern Saudi Arabia. The majority of the participants were females $(68.5 \%)$, the most common age group was (18-25) years old, $(57.6 \%)$ were single and (74.5\%) were highly educated. About (61.9\%) of them were in employment. Table 2 illustrates frequency distribution of student knowledge about hepatitis B infection. Of the students $75.5 \% \mathrm{knew}$ that HBV caused liver cancer, $81 \%$ of them knew that carriers could transmit infection $(89.5 \%$ of them said that it could not be spread by casual contact, $80 \%$ said it could be spread by contact with open wound, $96.5 \%$ knew it could be transmitted by contaminated blood and body fluids, $92.5 \%$ knew that HBV could be transmitted by unsterilized syringe, needle and surgical instruments and $79.5 \%$ said it could be transmitted by unsafe sex). Additionally, $86.5 \%$ of students knew that vaccine could prevent HBV infection, 95\% knew it had been laboratory tested, 64\% knew HBV had post exposure prophylaxisand only 55\% knew that it could be cured. Table 3 presents the frequency distribution of student attitude towards hepatitis B infection. A total of $23 \%$ of students said they have no concern of being infected with $\mathrm{HBV}, 86.5 \%$ agreed that $\mathrm{HBV}$ vaccine was safe and effective, 90\% believed that following infection, control guidelines would protect them from being infected by HBV at work. Table 4 illustrates frequency distribution of students practice about hepatitis B infection. Only $56.5 \%$ of students have screened for HBV infection. 22\% had sustained a needle prick injury but $68 \%$ would report that injury, $69.5 \%$ had received HBV vaccine $(38 \%$ of them had received 3 doses).

Table 1. Frequency distribution of medical student characteristics, NBU, 2017

\begin{tabular}{|l|l|l|l|}
\hline Variables & $\mathrm{n}$ & $\%$ \\
\hline Gender & Female & 125 & 62.5 \\
\cline { 2 - 4 } & Male & 75 & 37.5 \\
\hline Marital status & Divorced & 1 & .5 \\
\cline { 2 - 4 } & Married & 34 & 17.0 \\
\cline { 2 - 4 } & Single & 165 & 82.5 \\
\hline Student's academic year & $2^{\text {nd }}$ & 7 & 3.5 \\
\cline { 2 - 4 } & $3^{\text {rd }}$ & 30 & 15.0 \\
\cline { 2 - 4 } & $4^{\text {th }}$ & 36 & 18.0 \\
\cline { 2 - 4 } & $5^{\text {th }}$ & 25 & 12.5 \\
\hline & $6^{\text {th }}$ & 22 & 11.0 \\
\cline { 2 - 4 } & Intern & 80 & 40.0 \\
\hline
\end{tabular}

Table 2. Frequency distribution of student knowledge about hepatitis B infection, NBU, 2017

\begin{tabular}{|c|c|c|c|}
\hline \multicolumn{2}{|c|}{ Knowledge items } & $\mathrm{n}$ & $\%$ \\
\hline \multirow[t]{3}{*}{ HBV causes liver cancer } & Don't know & 16 & 8.0 \\
\hline & No & 33 & 16.5 \\
\hline & Yes & 151 & 75.5 \\
\hline \multirow[t]{3}{*}{ HBV carriers can transmit infection } & Don't know & 16 & 8.0 \\
\hline & No & 22 & 11.0 \\
\hline & Yes & 162 & 81.0 \\
\hline \multirow[t]{3}{*}{ HBV is spread by casual contact like hand shaking } & Don't know & 12 & 6.0 \\
\hline & No & 179 & 89.5 \\
\hline & Yes & 9 & 4.5 \\
\hline \multirow[t]{3}{*}{ HBV is spread by contact with open wound / cut } & Don't know & 12 & 6.0 \\
\hline & No & 27 & 13.5 \\
\hline & Yes & 161 & 80.5 \\
\hline \multirow[t]{3}{*}{ HBV can be transmitted by contaminated blood and body fluids } & Don't know & 4 & 2.0 \\
\hline & No & 3 & 1.5 \\
\hline & Yes & 193 & 96.5 \\
\hline \multirow[t]{3}{*}{ HBV be transmitted by unsterilized syringe, needle and surgical instruments } & Don't know & 8 & 4.0 \\
\hline & No & 7 & 3.5 \\
\hline & Yes & 185 & 92.5 \\
\hline
\end{tabular}




\begin{tabular}{|l|l|l|l|}
\hline HBV can be transmitted by unsafe sex & Don't know & 11 & 5.5 \\
\cline { 2 - 4 } & No & 30 & 15 \\
\cline { 2 - 4 } & Yes & 159 & 79.5 \\
\hline Vaccine can prevent HBV infection & Don't know & 6 & 3.0 \\
\cline { 2 - 4 } & No & 21 & 10.5 \\
\cline { 2 - 4 } & Yes & 173 & 86.5 \\
\hline HBV has been laboratory tested & Don't know & 9 & 4.5 \\
\cline { 2 - 4 } & No & 1 & .5 \\
\cline { 2 - 4 } & Yes & 190 & 95.0 \\
\hline HBV has post exposure prophylaxis & Don't know & 54 & 27.0 \\
\cline { 2 - 4 } & No & 18 & 9.0 \\
\cline { 2 - 4 } & Yes & 128 & 64.0 \\
\hline HBV can be cured / treated & Don't know & 37 & 18.5 \\
\cline { 2 - 4 } & No & 53 & 26.5 \\
\cline { 2 - 4 } & Yes & 110 & 55.0 \\
\hline
\end{tabular}

Table 3. Frequency distribution of student attitude towards hepatitis B infection, NBU, 2017

\begin{tabular}{|c|c|c|c|}
\hline \multicolumn{2}{|l|}{ Questions } & $\mathrm{n}$ & $\%$ \\
\hline \multirow[t]{3}{*}{ I have no concern of being infected with HBV } & Agree & 46 & 23.0 \\
\hline & Disagree & 125 & 62.5 \\
\hline & don't know & 29 & 14.5 \\
\hline \multirow[t]{3}{*}{ HBV vaccine is safe and effective } & Agree & 173 & 86.5 \\
\hline & Disagree & 12 & 6.0 \\
\hline & don't know & 15 & 7.5 \\
\hline \multirow[t]{3}{*}{ Change of the gloves during blood collection is a waste of time } & Agree & 23 & 11.5 \\
\hline & Disagree & 168 & 84.0 \\
\hline & don't know & 9 & 4.5 \\
\hline \multirow[t]{3}{*}{ All patients should be tested for HBV before they receive health care } & Agree & 115 & 57.5 \\
\hline & Disagree & 57 & 28.5 \\
\hline & don't know & 28 & 14.0 \\
\hline \multirow[t]{3}{*}{ I do not feel comfortable to take care of people with HBV } & Agree & 84 & 42.0 \\
\hline & Disagree & 100 & 50.0 \\
\hline & don't know & 16 & 8.0 \\
\hline \multirow[t]{3}{*}{ Following infection control guidelines will protect me from being infected by HBV at work } & Agree & 180 & 90.0 \\
\hline & Disagree & 7 & 3.5 \\
\hline & don't know & 13 & 6.5 \\
\hline
\end{tabular}

Table 4. Frequency distribution of students practice about hepatitis B infection, NBU, 2017

\begin{tabular}{|l|l|l|l|}
\hline \multicolumn{2}{|l|}{ Questions } & $\mathrm{n}$ & $\%$ \\
\hline Have you ever screened for HBV & No & 87 & 43.5 \\
\cline { 2 - 4 } & Yes & 113 & 56.5 \\
\hline I always change gloves for each patient during blood taking & No & 29 & 14.5 \\
\cline { 2 - 4 } & Yes & 171 & 85.5 \\
\hline Have you ever had a needle prick injury & No & 156 & 78.0 \\
\cline { 2 - 4 } & Yes & 44 & 22.0 \\
\hline I always report for needle prick injury & No & 64 & 32.0 \\
\hline Have you been vaccinated against HBV? & Yes & 136 & 68.0 \\
\hline How many doses of HBV vaccine did you receive & No & 61 & 30.5 \\
\cline { 2 - 4 } & Yes & 139 & 69.5 \\
\hline & Not received before & 57 & 28.5 \\
\cline { 2 - 4 } & One dose & 33 & 16.5 \\
\cline { 2 - 4 } & Three doses & 76 & 38.0 \\
\cline { 2 - 4 } & Two doses & 34 & 17.0 \\
\hline
\end{tabular}




\section{Discussion}

Hepatitis B virus (HBV) infection in the health setting is a global public health problem. The risk of occupational exposure to HBV among health care workers is a major concern, especially among students in health professions (17). This study was carried out to assess the knowledge regarding symptoms, risk factors and prevention of hepatitis B virus infection among medical students at Northern Border University, Arar, Kingdom of Saudi Arabia. Despite participants of the study having varied professional backgrounds, our results showed a high overall knowledge regarding $\mathrm{HBV}$, its mode of transmission and its prevention. In all, $81 \%$ of students knew that carriers could transmit infection $(89.5 \%$ of them said that it could not be spread by casual contact, $80 \%$ said it could be spread by contact with open wound, $96.5 \%$ knew it could be transmitted by contaminated blood and body fluids, 92.5\% knew that HBV could be transmitted by unsterilized syringe, needle or surgical instruments and $79.5 \%$ said it could be transmitted by unsafe sex). The findings were in accordance with a previous study from Cameroon, which reported that its participants had a good knowledge of the study on HBV infection (16). Another study on medical students in Northwest Ethiopia found that; most respondents knew that exposure to infected blood or body fluid, contaminated needles, contact with non-intact skin or unsafe sexual contacts were risk factors for HBV infection (17). These findings were in line with a study on nursing students attending tertiary care hospitals in Agartala city (18) who found that; the mean knowledge score of 16.2 , majority $(92.7 \%)$ knew that Hepatitis B was transmissible and $63.1 \%$ of them were aware that Hepatitis B transmission was possible through unsafe sex, infected blood/body fluid, contaminated syringe, needle or scalpel. A study among secondary school students in Côte d'Ivoire (19) found that; the causative agent of the disease was known by $74.1 \%$ of students, sexual transmission by $39.3 \%$, and bloodborne transmission by $57.2 \%$. Another study in Ethiopia reported that the knowledge regarding transmission of Hepatitis B through sexual route $(65.5 \%)$ by used needles and syringes $(71.7 \%)$ by blood transfusion $(89.8 \%)$ was high, but through vertical transmission (55.9\%) and contaminated water/food prepared by a person suffering with these infections (22\%) was low among overall medical and health science students (17). In our study, $86.5 \%$ of students knew that vaccine could prevent HBV infection. Furthermore, $95 \%$ knew it had been laboratory tested, $64 \%$ knew HBV had post exposure prophylaxis and only 55\% knew that it could be cured. Those findings were in accordance with a study by Abdela, Abdnur et al. (17) which found that (52.4\%) of students knew that HBV had treatments and $(67.1 \%)$ knew post-exposure prophylaxis. The findings are in accordance with a study in Pakistan, which discovered that knowledge regarding vaccine for hepatitis B was not satisfactory among the study groups (20). This indicates that there is a need to alleviate the gaps as these might affect seeking medical attention. A study among health care professionals in Pakistan (21) found that $75.3 \%$ of total participants knew it was preventable and $74.5 \%$ knew about vaccination. In the current study; $69.5 \%$ of students have received HBV vaccine (38\% of them received 3 doses). A study in Al-Jouf University (22) found only $52.1 \%$ medical students had been vaccinated and $37 \%$ were not sure, whereas $10.9 \%$ reported that they had never received an HBV vaccine. This was less than a study done in Brazil (59.3\%) (23) but higher than the study done in Sweden 40\% (24), Bangladesh (40.7\%) (25), Faculty of Medicine in Belgrade $24.1 \%$ (26), Nigeria 2.6\% (27). A study in Agartala city, India (18) reported that $(84.7 \%)$ respondents were vaccinated with three doses of Hepatitis B vaccine. On the other hand, a study by Abdela A et al. reported that only 5 (2\%) students had completed the three doses schedule of HBV vaccination (17). Ali A et al. (20) found that more than $50 \%$ of the students had received a Hepatitis B vaccination, but a large number of them did not have enough knowledge about the vaccine itself. In a study in Ethiopia, it was reported that $13.4 \%$ of its participants received one or more doses of the hepatitis B vaccine, among whom $4.7 \%$ of the students were completely vaccinated against HBV (27). This figure was lower than the vaccination status of $87.8 \%$ from a study carried out at the Muhammad Medical College in Mirpur Khas, Pakistan (26), the 29.3\% which was reported among medical students in a study at the B.J. Medical College in Pune, India (29) together with the $35 \%$ reported in a study at a civil hospital of 60 laboratory technicians (30), the $63 \%$ reported in a study of medical students from India and the $42 \%$ which was reported in a study among medical students of Lahore (31). In this study; about $22 \%$ had a needle prick injury but $68 \%$ would report that injury. This finding suggests that there is an obligation to address the inconsistency by establishing better health education on universal safety precautions for the prevention of infections. Our results were in line with the Ethiopian study (17) which found that $28.6 \%$ of participants had been exposed to blood accidentally; and $46.3 \%$ had no intention to report the accident. The finding of a $28.6 \%$ rate of accidental exposure to blood was lower than the $55.9 \%$ rate reported from Cameroon (16), the $40 \%$ from Palestine (32) and the $48 \%$ rate from Nigeria (33).

\section{Conclusions}

The students' knowledge of the hepatitis B virus was found to be good. Based on that; the percentage of infected students is predicted to be as low as the knowledge of modes of transmission. We recommend improving knowledge, attitude and practice of the public as well as students through the health education campaigns and 
settings. Prevention programs about HBV should be instituted and the existing ones must be strengthened, and health education settings should be more specific and clear for the public and students. Adequate commitment from the Ministry of Health is also advocated.

\section{Acknowledgments:}

The success and final outcome of this work required support and assistance of many people and we are fortunate to have had this throughout the completion of the work. My thanks go to Dr. Nagah Mohamed Abo El- Fetoh (Associate Professor of Community Medicine, NBU) for her help in different steps of the research.

\section{Conflict of Interest:}

There is no conflict of interest to be declared.

\section{Authors' contributions:}

All authors contributed to this project and article equally. All authors read and approved the final manuscript.

\section{References:}

1) Schillie S, Murphy TV, Sawyer M, Ly K, Hughes E, Jiles R, et al. CDC guidance for evaluating health-care personnel for hepatitis $\mathrm{B}$ virus protection and for administering post exposure management. MMWR Recomm Rep. 2013; 62: 1-19. PMID: 24352112.

2) Abedi F, Madani H, Asadi A, Nejatizadeh A. Significance of blood-related high-risk behaviors and horizontal transmission of hepatitis B virus in Iran. Arch Virol. 2011; 156: 629-35. doi: 10.1007/s00705010-0902-y. PMID: 21229276.

3) Hepatitis B. Fact sheet N²04. WHO. 2014.

4) Fairley CK, Read TR. Vaccination against sexually transmitted infections. Curr Opin Infect Dis. $2012 ; 25$ (1): 66-72. doi: 10.1097/QCO.0b013e32834e9aeb. PMID: 22143117.

5) Hughes RA. Drug injectors and the cleaning of needles and syringes. Eur Addict Res. 2000; 6 (1): $20-30$. doi: 10.1159/000019005. PMID: 10729739.

6) Buddeberg F, Schimmer BB, Spahn DR. Transfusion-transmissible infections and transfusion-related immunomodulation. Best Pract Res Clin Anaesthesiol. 2008; 22 (3): 503-17. doi: 10.1016/j.bpa.2008.05.003. PMID: 18831300.

7) Wilkins T, Zimmerman D, Schade RR. Hepatitis B: Diagnosis and treatment. Am Fam Physician. 2010; 81: 965-72. PMID: 20387772.

8) Causse X, Delaunet A, Si Ahmed SN. Anaes practice guidelines for vaccination against hepatitis B virus: Impact on general practitioners. Gastroenterol Clin Biol. 2009; 33: 1166-70. doi: 10.1016/j.gcb.2009.10.010. PMID: 19942392.

9) Rachiotis G, Goritsas C, Alikakou V, Ferti A, Roumeliotou A. Vaccination against hepatitis B virus in workers of a general hospital in Athens. Med Lav. 2005; 96(1): 80-6. PMID: 15847111.

10) Molinari J. Infection control. Its evolution to the current standard precautions. J Am Dent Assoc. 2003; 134(5): 569-74. doi: 10.14219/jada.archive.2003.0222.

11) World Health Organization. Health Care Worker Safety. Available from: http://www.who.int/occupational_health/activities/1am_hcw.pdf.

12) Hutin Y, Hauri A, Chiarello L, Catlin M, Stilwell B, Ghebrehiwet T, et al. Best infection control practices for intradermal, subcutaneous, and intramuscular needle injections. Bull World Health Organ. 2003; 7: 491-500.

13) Alqahtani JM, Abu-Eshy SA, Mahfouz AA, El-Mekki AA, Asaad AM. Seroprevalence of hepatitis B and C virus infections among health students and health care workers in the Najran region, southwestern Saudi Arabia: the need for national guidelines for health students. BMC Public Health. 2014; 14: 577 . doi: 10.1186/1471-2458-14-577. PMID: 24912684, PMCID: PMC4059075.

14) Al-Ajlan A. Prevalence of hepatitis B and C among students of health colleges in Saudi Arabia. East Mediterr Health J. 2011; 17: 759-62. PMID: 22256410.

15) Mueller A, Stoetter L, Kalluvya S, Stich A, Majinge C, Weissbrich B, et al. Prevalence of Hepatitis B Virus Infection among Health Care Workers in a Tertiary Hospital in Tanzania. BMC Infect Dis. 2015; 15: 386. doi: 10.1186/s12879-015-1129-z. PMID: 26399765, PMCID: PMC4581415.

16) Noubiap JJ, Nansseu JR, Kengne KK, Ndoula ST, Agyingi LA. Occupational exposure to blood, hepatitis $B$ vaccine knowledge and uptake among medical students in Cameroon. BMC Med Educ. 2013; $13: 148$. doi: 10.1186/1472-6920-13-148. 
17) Abdela A, Woldu B, Haile K, Mathewos B, Deressa T. Assessment of Knowledge, Attitudes and Practices toward Prevention of Hepatitis B Virus Infection among Students of Medicine and Health Sciences in Northwest Ethiopia. BMC Research Notes. 2016; 9(1): 410. doi: 10.1186/s13104-016-2216-y. PMID: 27543117, PMCID: PMC4992214.

18) Reang T, Chakraborty T, Sarker M, Tripura A. A study of knowledge and practice regarding Hepatitis B among nursing students attending tertiary care hospitals in Agartala city. Int J Res Med Sci. 2015; 3(7): 1641-9. doi: 10.18203/2320-6012.ijrms20150244.

19) Lohouès-Kouacou MJ, Assi C, Ouattara A, Bonao SG, Koné S, Soro D, et al. [Hepatitis B knowledge among secondary school students in Côte d'Ivoire]. Sante Publique. 2013; 25(2): 227-32. PMID: 23964548.

20) Ali A, Khan S, Malik SM, Haris Iqbal M, Aadil M. Comparison of Knowledge and Attitudes Regarding Hepatitis B Among Healthcare Professionals in Pakistan. Cureus. 2017; 9(2): e1049. doi: 10.7759/cureus.1049. PMID: 28367387, PMCID: PMC5364084.

21) Rehman R, Iqbal A, Syed S, Kamran A. Evaluation of integrated learning program of undergraduate medical students. Pak J Physiol. 2011; 7: 37-41.

22) Al-Hazmi AH. Knowledge, Attitudes, and Practice of Medical Students Regarding Occupational Risks of Hepatitis B Virus in College of Medicine, Aljouf University. Ann Med Health Sci Res. 2015; 5(1): 13-9. doi: 10.4103/2141-9248.149765. PMID: 25745570, PMCID: PMC4350056.

23) Oliveira LC, Pontes JP. Frequency of hepatitis B immunity and occupational exposures to body fluids among Brazilian medical students at a public university. Rev Inst Med Trop Sao Paulo. 2010; 52: $247-52$. doi: 10.1590/S0036-46652010000500005.

24) Dannetun E, Tegnell A, Torner A, Giesecke J. Coverage of hepatitis B vaccination in Swedish healthcare workers. J Hosp Infect. 2006; 63: 201-4. doi: 10.1016/j.jhin.2006.01.014. PMID: 16621139.

25) Ahmed MS, Chowdhury OA, Chowdhury AR, Khatoon M. Seroprevalence of HBs antibody among the newly admitted medical students in Bangladesh and seroconversion one year after vaccination. Bangladesh Med Res Counc Bull. 2010; 36: 41-2. doi: 10.3329/bmrcb.v36i1.5264. PMID: 21280561.

26) Denic LM, Ostric I, Pavlovic A, Dimitra KO. Knowledge and occupational exposure to blood and body fluids among health care workers and medical students. Acta ChirIugosl. 2012; 59: 71-5. doi: 10.2298/ACI1201071M. PMID: 22924308.

27) Odusanya OO, Meurice FP, Hoet B. Nigerian medical students are at risk for hepatitis B infection. Trans R Soc Trop Med Hyg. 2007; 101: 465-8. doi: 10.1016/j.trstmh.2006.08.001. PMID: 17011004.

28) Mesfin YM, Kibret KT. Assessment of Knowledge and Practice towards Hepatitis B among Medical and Health Science Students in Haramaya University, Ethiopia. PLoS One. 2013; 8(11): e79642. doi: 10.1371/journal.pone.0079642. PMID: 24278151, PMCID: PMC3836877.

29) Muhammad A, Waseem R, Zulfikar AG. Hepatitis B vaccination coverage in medical studentsat a medical college of Mirpurkhas. J Pak Med Assoc. 2011; 61(7): 680-2.

30) Bharti K, Lala MK. A study of knowledge, attitude and practice of hepatitis-B infection among the laboratory technicians in the civil hospital, Ahmedabad, Gujarat. Health line. 2012; 3(1): 63-5.

31) Biju IK, Sattar A, Kate M. Incidence and awareness of hepatitis B infection among paramedical students. Indian J Gastroenterol. 2002; 21(1): 104-5.

32) Al-Dabbas M, Abu-Rmeileh NM. Needle stick injury among interns and medical students in the occupied Palestine territory. East Mediterr Health J. 2012; 18(7): 700-706. PMID: 22891516.

33) Okeke EN, Ladep NG, Agaba EI, Malu AO. Hepatitis B vaccination status and needle stick injuries among medical students in a Nigerian University. Niger J Med. 2008; 17(3): 330-2. doi: 10.4314/njm.v17i3.37404. 